\title{
Degradation of 2,4-Dichlorobenzoic Acid by Coupled Electrocatalytic Reduction and Anodic Oxidation
}

\author{
Ning Li, Xiaozhe Song, Hui Wang ${ }^{*}$ \\ College of Environmental Science and Engineering, Beijing Forestry University, Beijing 100083, PR \\ China \\ *E-mail: wanghui@bjfu.edu.cn
}

doi: $10.20964 / 2020.06 .30$

Received: 4 January 2020 / Accepted: 12 March 2020 / Published: 10 May 2020

\begin{abstract}
Dual effects of cathodic dechlorination and oxidative decomposition of 2,4-dichlorobenzoic acid (2,4DCBA) can be achieved using electrochemical reduction-oxidation technology. The removal efficiency was improved by optimizing the experimental conditions affecting electrode activity and contaminant degradation. The 2,4-DCBA removal efficiency reached $90.8 \%$ at a current density at $50 \mathrm{~mA} \cdot \mathrm{cm}^{-2}$, initial $\mathrm{pH}$ of 5 , and sodium sulfate concentration of $0.05 \mathrm{~mol} \cdot \mathrm{L}^{-1}$, with a $2,4-\mathrm{DCBA}$ concentration of $20 \mathrm{mg} \cdot \mathrm{L}^{-}$ 1. Furthermore, a good total organic carbon removal efficiency of $81.6 \%$ was achieved in the electrocatalytic reduction and oxidation process, with the present system retaining high stability after many experiment cycles. The reaction mechanism under different conditions is discussed, which provides new approaches to the degradation of chlorinated organic compounds.
\end{abstract}

Keywords: 2,4-dichlorobenzoic acid, electrochemical reduction-oxidation, optimal conditions, dechlorination, oxidation reaction

\section{FULL TEXT}

(C) 2020 The Authors. Published by ESG (www.electrochemsci.org). This article is an open access article distributed under the terms and conditions of the Creative Commons Attribution license (http://creativecommons.org/licenses/by/4.0/). 